\title{
A Selenium Nanocomposite Protects the Mouse Brain from Oxidative Injury Following Intracerebral Hemorrhage
}

This article was published in the following Dove Press journal: International Journal of Nanomedicine

\author{
Yong Yang $\mathbb{D}^{1, *}$ \\ Guoying Deng $\mathbb{D}^{2, *}$ \\ Peng Wang' \\ Guangzhao Lv' \\ Rui Mao' \\ Yuhao Sun ${ }^{3}$ \\ Baofeng Wang ${ }^{3}$ \\ Xijian Liu (iD ${ }^{4}$ \\ Liuguan Bian ${ }^{3}$ \\ Dong Zhou (D) \\ 'Department of Neurosurgery, Guangdong \\ Provincial People's Hospital, Guangdong \\ Academy of Medical Sciences, Guangzhou, \\ 510080, People's Republic of China; \\ ${ }^{2}$ Trauma Center, Shanghai General \\ Hospital, Shanghai Jiao Tong University, \\ School of Medicine, Shanghai, 201620, \\ People's Republic of China; ${ }^{3}$ Department of \\ Neurosurgery, Ruijin Hospital, Shanghai \\ Jiao Tong University, School of Medicine, \\ Shanghai, 200025, People's Republic of \\ China; ${ }^{4}$ College of Chemistry and Chemical \\ Engineering, Shanghai University of \\ Engineering Science, Shanghai, 201620, \\ People's Republic of China \\ *These authors contributed equally to this \\ work
}

Correspondence: Liuguan Bian Department of Neurosurgery, Ruijin Hospital, Shanghai Jiao Tong University, School of Medicine, 197 Rui Jin Er Road, Shanghai, 200025, People's Republic of China Tel +86 2l 64370045 Ext 66609 I

Fax +862164333548

Email blgIIII8@rih.com.cn

Dong Zhou

Department of Neurosurgery, Guangdong Provincial People's Hospital, Guangdong Academy of Medical Sciences, No. 106

Zhongshan Er Road, Yuexiu District, Guangzhou, 510080, People's Republic of China

$\mathrm{Tel}+8620838278 \mid 2$ Ext 6152I

Email zhoudong54I3@I63.com
Background: Intracerebral hemorrhage (ICH) is a common neurological crisis leading to high mortality and morbidity. Oxidative stress-induced secondary injury plays a critical role in neurological deterioration. Previously, we synthesized a porous $\mathrm{Se} @ \mathrm{SiO}_{2}$ nanocomposite and identified their therapeutic role in osteonecrosis of the femoral head. Whether this nanocomposite is neuroprotective remains to be elucidated.

Methods: A porous $\mathrm{Se} @ \mathrm{SiO}_{2}$ nanocomposite was synthesized, and its biosafety was determined using a CCK-8 assay. The neuroprotective effect was evaluated by TUNEL staining, and intracellular ROS were detected with a DCFH-DA probe in SH-SY5Y cells exposed to hemin. Furthermore, the effect of the nanocomposite on cell apoptosis, brain edema and blood-brain barrier permeability were evaluated in a collagenase-induced ICH mouse model. The potential mechanism was also explored.

Results: The results demonstrated that $\mathrm{Se} @ \mathrm{SiO}_{2}$ treatment significantly improved neurological function, increased glutathione peroxidase activity and downregulated malonaldehyde levels. The proportion of apoptotic cells, brain edema and blood-brain barrier permeability were reduced significantly in ICH mice treated with $\mathrm{Se} @ \mathrm{SiO}_{2}$ compared to vehicle-treated mice. In vitro, $\mathrm{Se} @ \mathrm{SiO}_{2}$ protected $\mathrm{SH}-\mathrm{SY} 5 \mathrm{Y}$ cells from hemin-induced apoptosis by preventing intracellular reactive oxygen species accumulation.

Conclusion: These results suggested that the porous $\mathrm{Se} @ \mathrm{SiO}_{2}$ nanocomposite exerted neuroprotection by suppressing oxidative stress. $\mathrm{Se} @ \mathrm{SiO}_{2}$ may be a potential candidate for the clinical treatment of $\mathrm{ICH}$ and oxidative stress-related brain injuries.

Keywords: selenium nanocomposites, oxidative stress, blood-brain barrier, brain edema, apoptosis

\section{Introduction}

Intracerebral hemorrhage $(\mathrm{ICH})$ is a common type of hemorrhagic stroke that causes mortality and morbidity in patients. ${ }^{1}$ Most survivors have varying degrees of neurological dysfunction. Oxidative stress-induced secondary injury plays critical roles in blood-brain barrier (BBB) disruption, cerebral edema and neurological deterioration. $^{2-4}$

Oxidative stress results from the imbalance between oxidant (reactive oxygen species, ROS) production and the antioxidant capacity of cells. Hemin, which is the product of hemoglobin breakdown, is an inducer of ROS. ${ }^{5,6}$ Excessive ferrous iron was liberated during hemin degradation. By cycling in the Fenton reaction, ferrous iron catalyzes the production of large amounts of hydroxyl radicals, which lead to 
lipid peroxidation and cell apoptosis. Protective measures against oxidative injury in the context of ICH have been found to be effective in ameliorating neurological dysfunction. $^{7-10}$

Ceria nanoparticles and their nanocomposites have exhibited effective results in protecting against cerebral ischemia injury by scavenging ROS. ${ }^{11,12}$ However, selenium (Se), as an essential micronutrient, has an advantage over ceria. $\mathrm{Se}$ is a cofactor of glutathione peroxidase (GSH-Px) and thioredoxin reductase, which are antioxidant enzymes that defend against oxidative stress and maintain the redox balance. ${ }^{13}$ However, the application of Se is limited due to the narrow margin between beneficial and toxic effects. ${ }^{14}$ When materials are engineered into nanoparticles, they acquire unique physical and chemical properties. Elemental selenium at the nanoscale has been shown to have higher bioactivity and lower toxicity compared to other forms. ${ }^{15,16}$ The bioactivity is highly relevant to the size of the nanoparticles, and it has been reported that nano-Se with a diameter of 5-200 nm can directly scavenge free radicals in vitro in a size-dependent manner. ${ }^{17}$ To further reduce the toxic effects, researchers have tried to synthesize nanoparticles by the green method. ${ }^{18-23}$ Nonetheless, the toxicity of Se is still not negligible in the treatment. With these considerations, Liu and colleagues fabricated porous $\mathrm{Se} @ \mathrm{SiO}_{2}$ nanocomposites with an average diameter of $\sim 55 \mathrm{~nm}^{24}$ The particles had good biosafety due to the controlled release of Se, which can guarantee beneficial effects and reduce toxicity. Moreover, they have been proven to be therapeutic in osteonecrosis of the femoral head. ${ }^{25}$ However, their neuroprotective effect in the context of ICH has not been investigated.

In this study, $\mathrm{Se} @ \mathrm{SiO}_{2}$ was administered by intraperitoneal injection in ICH mice, and blood-brain barrier penetration, oxidative stress markers, cell apoptosis, BBB disruption, brain edema and neurological function were evaluated. The neuroprotection of $\mathrm{Se} @ \mathrm{SiO}_{2}$ was also studied in vitro based on the neuroblastoma cell line SHSY5Y, and the potential mechanisms were explored.

\section{Materials and Methods}

\section{Synthesis and Characterization of $\mathrm{Se} @ \mathrm{SiO}_{2}$}

Porous $\mathrm{Se} @ \mathrm{SiO}_{2}$ nanoparticles were synthesized as described previously. ${ }^{24}$ The average particle size and morphology were observed using transmission electron microscopy (TEM; JEM-2100F). The $\mathrm{Se} @ \mathrm{SiO}_{2}$ nanoparticles were characterized using a D/max-2550 PC X-ray diffractometer (XRD; Rigaku, $\mathrm{Cu}-\mathrm{K} \alpha$ radiation). The porous $\mathrm{Se} @ \mathrm{SiO}_{2}$ nanocomposite was dispersed in phosphate buffered solution (PBS) to make a stock of $10 \mathrm{mg} / \mathrm{mL}$ and stored at $4{ }^{\circ} \mathrm{C}$ for further use.

\section{Cell Culture}

Because primary neurons cannot be trypsinized and reseeded, the human neuroblastoma cell line SH-SY5Y may be adopted as a substitution in the study of neurotoxicity. The SH-SY5Y cell line was purchased from the Cell Bank of the Chinese Academy of Sciences (Shanghai, China). The cells were cultured in Dulbecco's modified Eagle medium (DMEM) supplemented with 10\% fetal bovine serum and maintained in a humidified incubator at $37{ }^{\circ} \mathrm{C}$ in a $5 \% \mathrm{CO}_{2}$ atmosphere. For flow cytometry analysis and microscopic observation, the cells were trypsinized and plated at a density of $1 \times 10^{6} /$ well in 6-well plates or $5 \times 10^{4} /$ well in 24 -well plates.

\section{Cell Viability Assay}

Cell viability was determined using a Cell Counting Kit-8 (CCK-8) (DOJINDO, Japan) assay. SH-SY5Y cells were seeded at a density of $1 \times 10^{4} /$ well in 96 -well plates. The cells were exposed to $0,3.125,6.25,12.5,25,50,100$, $200,400,800$, or $1600 \mu \mathrm{g} / \mathrm{mL} \mathrm{Se} @ \mathrm{SiO}_{2}$ for $24 \mathrm{~h}$. Then, 10 $\mu \mathrm{L}$ of CCK-8 solution was added into each well. After incubating for $4 \mathrm{~h}$ at $37^{\circ} \mathrm{C}$. The absorbance at $450 \mathrm{~nm}$ was measured using a microplate reader (BioTek, USA). For additional experiments, SH-SY5Y cells were pretreated with or without $100 \mu \mathrm{g} / \mathrm{mL} \mathrm{Se} @ \mathrm{SiO}_{2}$ for $12 \mathrm{~h}$ and then exposed to $0,6.25,12.5,25$, or $50 \mu \mathrm{M}$ hemin for $24 \mathrm{~h}$.

\section{In situ Cell Death Detection}

A TdT-dUTP nick-end labeling (TUNEL) assay was conducted to detect apoptotic cells using a one-step in situ cell death detection kit (Roche, Germany). After fixation in 4\% paraformaldehyde, the treated cells or brain slices were washed twice in PBS and incubated with $0.1 \%$ Triton $\mathrm{X}-100$ for $2 \mathrm{~min}$ on ice. Then, the cells or slices were incubated in TUNEL reaction mixture for $1 \mathrm{~h}$ at $37{ }^{\circ} \mathrm{C}$ in the dark. The nuclei were counterstained with DAPI (1:5000, Invitrogen, USA). Fluorescence images were captured by an experimenter who was blinded to the treatment conditions using a confocal laser-scanning microscope (Leica, Germany). Eight pictures were taken randomly in the perihematomal area of each sample. TUNEL-positive 
cells showing red fluorescence were considered apoptotic cells. The percentage of TUNEL-positive cells was quantified, and the average was calculated.

\section{Flow Cytometry Analysis of Cell Apoptosis}

SH-SY5Y cells were seeded onto 6-well plates, pretreated with or without 25 or $100 \mu \mathrm{g} / \mathrm{mL} \mathrm{Se} @ \mathrm{SiO}_{2}$ for $12 \mathrm{~h}$, and then exposed to $25 \mu \mathrm{M}$ hemin for $24 \mathrm{~h}$. Apoptosis was analyzed by flow cytometry using a FITC Annexin V Apoptosis Detection Kit I (BD, USA). Briefly, the treated cells were harvested and stained according to the manufacturer's instructions. Then, the samples were analyzed using Guava EasyCyte Plus (Millipore, United States) within 30 min after staining.

\section{Detection of ROS}

SH-SY5Y cells were pretreated with or without 25 or $100 \mu \mathrm{g} / \mathrm{mL} \mathrm{Se} @ \mathrm{SiO}_{2}$ for $12 \mathrm{~h}$ and then exposed to 25 $\mu \mathrm{M}$ hemin for $12 \mathrm{~h}$. ROS reactive fluorescence staining was performed as previously described. ${ }^{26}$ Briefly, after treatment, the cells were incubated with $10 \mu \mathrm{M} \mathrm{DCFH-}$ DA (Beyotime Biotechnology, China) in serum-free DMEM for $20 \mathrm{~min}$ at $37{ }^{\circ} \mathrm{C}$. The cells were washed 3 times with PBS and observed using a confocal laserscanning microscope (Leica, Germany) or analyzed using FACScan (Beckman Coulter Cell, Brea, CA, USA).

\section{$\mathrm{ICH}$ Mouse Model Preparation and Treatment}

This study was conducted in accordance with the Institutional Guidelines on Animal Welfare issued by the Ministry of Science and Technology of the People's Republic of China on September 30th, 2006. All the animal procedures were approved by the Research Ethics Committee of Guangdong Provincial People's Hospital. Male C57BL/6 mice (weight 23-25 g; age of 8 weeks; SPF class) were obtained from the Guangdong Medical Laboratory Animal Center. The mice were bred and maintained under a 12/12-hour light-dark cycle with free access to food and water. The room temperature was set to $18^{\circ} \mathrm{C}-$ $25^{\circ} \mathrm{C}$, and the relative humidity was set to $40-60 \%$. The ICH mouse model was established by intrastriatal injection of collagenase IV as previously described. ${ }^{27}$ Under general anesthesia [ketamine $(100 \mathrm{mg} / \mathrm{kg})$, xylazine $(10 \mathrm{mg} / \mathrm{kg})]$, the mice were secured in a stereotaxic frame (RWD Life
Science Co., Shenzhen, China). A $1.0 \mathrm{~mm}$ cranial burr hole was drilled $0.2 \mathrm{~mm}$ anterior to the bregma and $2.5 \mathrm{~mm}$ lateral to the midline. A 30-gauge needle was inserted $3.0 \mathrm{~mm}$ into the right striatum. Collagenase IV (Sigma-Aldrich, USA) ( $0.075 \mathrm{U}$ dissolved in $0.4 \mu \mathrm{L}$ saline) was injected at a rate of $0.25 \mu \mathrm{L} / \mathrm{min}$ over $90 \mathrm{sec}$ using a microinfusion pump. The needle was left in place for 5 min to prevent the backflow of collagenase. After withdrawal of the needle, the hole was sealed with bone wax, and the scalp was sutured. Sham-operated mice received needle insertion only.

The mice were randomly divided into sham, vehicletreated, $0.5 \mathrm{mg} / \mathrm{kg} \mathrm{Se} @ \mathrm{SiO}_{2}$ and $1 \mathrm{mg} / \mathrm{kg} \mathrm{Se} @ \mathrm{SiO}_{2^{-}}$ treated groups according to a random number table. The maximal dose of $\mathrm{Se} @ \mathrm{SiO}_{2}$ was determined based on our previous study. ${ }^{25}$ In the $\mathrm{Se} @ \mathrm{SiO}_{2}$-treated groups, $0.5 \mathrm{mg} / \mathrm{kg} \mathrm{Se} @ \mathrm{SiO}_{2}$ and $1 \mathrm{mg} / \mathrm{kg} \mathrm{Se} @ \mathrm{SiO}_{2}$ (in $100 \mu \mathrm{L}$ PBS) were given to mice by intraperitoneal injection 0.5 $\mathrm{h}$ post ICH induction. Our previous study revealed that $\mathrm{Se} @ \mathrm{SiO}_{2}$ had good blood-brain barrier penetration, and there was no significant difference in its distribution in different brain regions (refer to Supplementary materials, Evaluation of the BBB penetration of $\mathrm{Se} @ \mathrm{SiO}_{2}$ and the results are shown in Figure S1). Equal volumes of PBS were injected intraperitoneally into the vehicle-treated group. After the initial injection, the treatment was repeated every $24 \mathrm{~h}$ until sacrificing. The injection interval was based on the kinetics of $\mathrm{Se} @ \mathrm{SiO}_{2}$ in the brain tissue (Supplementary materials Figure S1).

\section{Behavioral Assessment}

Behavioral assessments were conducted by two observers who were blinded to treatment conditions on 1, 3, 5 and 7 $\mathrm{d}$ post ICH. The total neurological score was calculated according to the criteria described by Zeng et $\mathrm{al}^{28}$ which included motor, sensory, balance, and reflex tests (neurological intact score, 0 ; most severe deficit score, 14).

The vestibulomotor function of the mice was evaluated by the rotarod test. Before ICH induction, the mice were trained at a low speed $(10 \mathrm{rpm})$. After habituation, the speed was adjusted to $40 \mathrm{rpm}$. All mice were trained twice per day. The average time of falling in the final three training sessions was recorded as the baseline. After 3 days of training, the animals were subjected to the surgical procedure. After $\mathrm{ICH}$, the mice were tested 3 times on days $1,3,5$, and 7 , and the average time to fall was recorded. 


\section{Measurement of Evans Blue}

BBB permeability was evaluated $3 \mathrm{~d}$ post ICH by measuring the extravasation of Evans blue. Evans blue (2\%) was injected intravenously at a dose of $4 \mathrm{~mL} / \mathrm{kg} 2 \mathrm{~h}$ prior to sacrificing. Then, the intravascular localized dye was removed by perfusion through the left ventricle. The brains were collected and dissected into left and right hemispheres. Each hemisphere was weighed and homogenized in $1 \mathrm{~mL}$ of $50 \%$ trichloroacetic acid solution. After centrifugation at $21,000 \times \mathrm{g}$ for $20 \mathrm{~min}$, the supernatant was diluted 1:3 with ethanol, and its absorbance was measured at $610 \mathrm{~nm}$. The amount of Evans blue dye was calculated against a standard curve and expressed as the ipsilateral/ contralateral ratio.

\section{Measurement of the Brain Water Content}

The mice were sacrificed $3 \mathrm{~d}$ post $\mathrm{ICH}$, and brain tissues were collected. The samples were weighed before and after dehydration in an oven at $100^{\circ} \mathrm{C}$ for $24 \mathrm{~h}$. The brain water content $(\%)$ was calculated as [(wet weightdry weight) $/$ wet weight] $\times 100 \%$.

\section{Determination of Oxidative Stress}

\section{Factors}

The product of lipid peroxidation (malonaldehyde, MDA) and the activity of glutathione peroxidase (GSH-Px) were determined using commercial MDA and GSH-Px kits (Beyotime Biotechnology, China). In brief, mice were sacrificed under deep pentobarbital anesthesia $3 \mathrm{~d}$ after $\mathrm{ICH}$, and segments of the perihematoma of the right hemispheres were harvested. Then, the brain tissues were homogenized in ten volumes of PBS on ice. The homogenates were centrifuged at $14,000 \times \mathrm{g}$ for $20 \mathrm{~min}$ at $4{ }^{\circ} \mathrm{C}$, and the protein concentration of the supernatant was determined by a Pierce ${ }^{\mathrm{TM}}$ BCA Protein Assay Kit (Thermo Fisher Scientific, USA). The MDA concentration and GSH-Px activity were measured following the manufacturer's instructions.

\section{Western Blot Analysis}

Mice were sacrificed $3 \mathrm{~d}$ after ICH, segments of the perihematoma of the right hemispheres were harvested, and tissue lysates were prepared using RIPA lysis buffer (Merck Millipore, Germany) supplemented with protease inhibitor cocktail (Roche, Switzerland) and $1 \mathrm{mM}$ phenylmethanesulfonyl fluoride (PMSF) (Sigma, MO, USA). The protein concentrations were determined by a Pierce ${ }^{\mathrm{TM}}$ BCA Protein Assay Kit (Thermo Fisher Scientific, USA). Equal amounts of protein $(30 \mu \mathrm{g})$ were separated by standard sodium dodecyl sulfate polyacrylamide gel electrophoresis and then electrotransferred onto PVDF membranes. The blots were blocked with $5 \%$ nonfat milk and incubated with primary antibodies against iNOS (1:1000, Abcam, UK), AQP4 (1:200, Santa Cruz Biotechnology, USA), ZO-1 (1:1000, Invitrogen, USA), occludin (1:1000, Invitrogen, USA), Bcl2 (1:1000, Cell Signaling Technology, USA), Bax (1:1000, Cell Signaling Technology, USA), caspase 3 (1:1000, Cell Signaling Technology, USA), cleaved caspase 3 (1:1000, Cell Signaling Technology, USA) and GAPDH (1:2000, Cell Signaling Technology, USA) at $4^{\circ} \mathrm{C}$ overnight. After washing, the membranes were incubated with appropriate secondary antibodies $(1: 10,000$, Invitrogen, USA) for $1 \mathrm{~h}$ at room temperature. After washing, the membranes were incubated with ECL solution (Thermo Fisher Scientific, USA) for $3 \mathrm{~min}$. The signal was detected using a Tanon imaging system (Shanghai, China). Densitometric analysis of the bands was performed using ImageJ 1.6.0 (NIH, USA).

\section{Statistical Analysis}

All data are presented as the mean \pm standard deviation (SD). Statistical comparisons were performed using one-way ANOVA followed by Bonferroni's multiple comparisons. $P$-values $<0.05$ were considered statistically significant. Statistical analysis and graph drawing were performed using GraphPad Software Prism 5.0 (GraphPad Software, CA, USA).

\section{Results}

\section{Physical and Chemical Properties of the Se@SiO 2 Nanocomposite}

The phase structure of the nanoparticles was examined by XRD. As shown in Figure 1A, several well-defined characteristic peaks, such as (100), (011), (012) and (021), exhibited the hexagonal phase and indicated strong $\mathrm{Se}$ signals for the standard Se phase. The morphology of the $\mathrm{Se} @ \mathrm{SiO}_{2}$ nanocomposite was observed by TEM, showing an average diameter of $\sim 55 \mathrm{~nm}$ (Figure 1B). As shown in Figure 1C, many Se nanocrystals (with diameters less than $5 \mathrm{~nm}$ ) were interspersed from the center to the surface in the $\mathrm{Se} @ \mathrm{SiO}_{2}$ nanocomposites. After etching in hot water, the $\mathrm{Se} @ \mathrm{SiO}_{2}$ nanocomposites became porous structures (Figure 1D). Se could undergo slow sustained release from the $\mathrm{Se} @ \mathrm{SiO}_{2}$ nanocomposites, which could control 

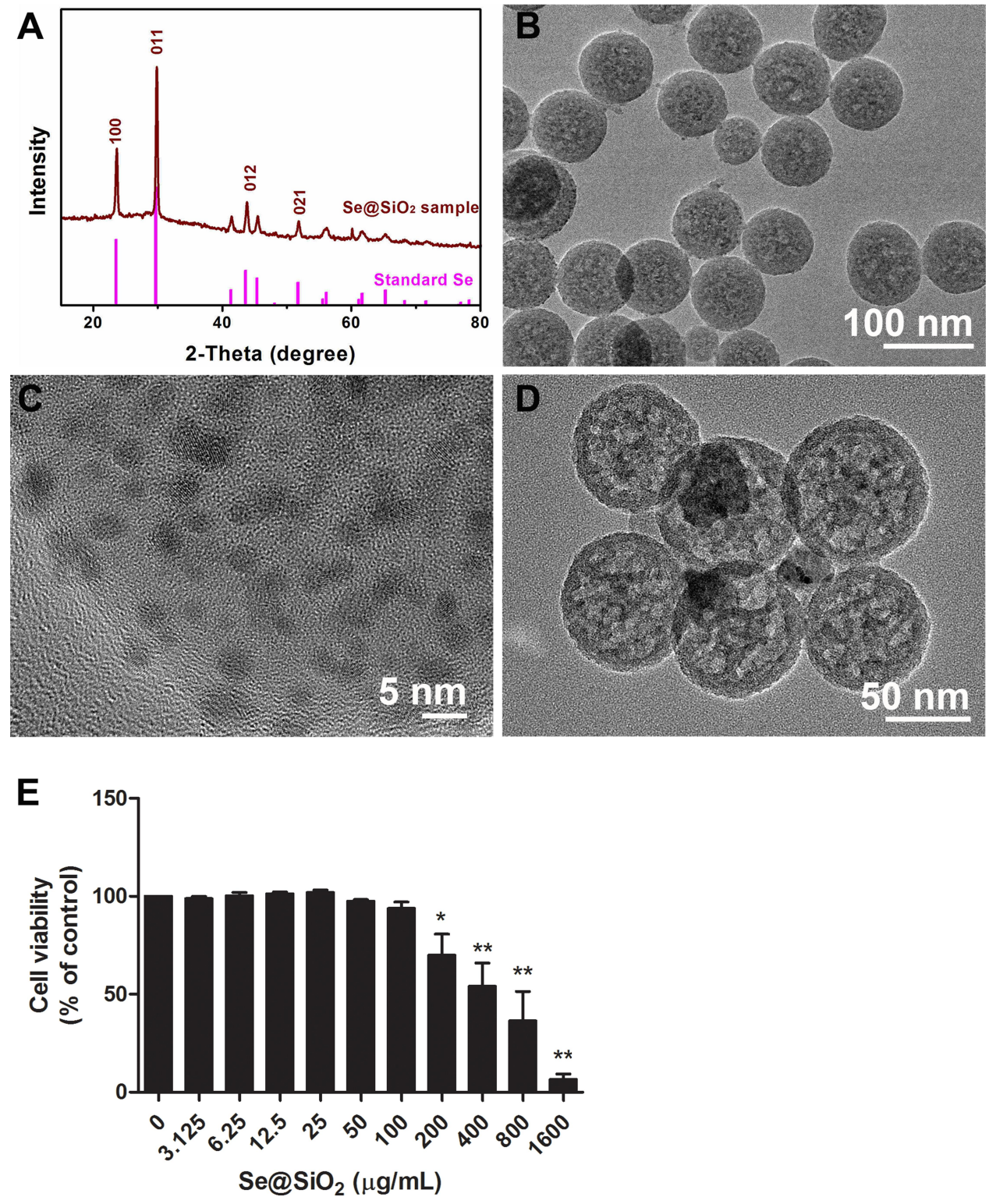

Figure I Characterization of the $\mathrm{Se} @ \mathrm{SiO}_{2}$ nanocomposite and confirmation of its biosafety.

Notes: (A) XRD pattern of the Se@SiO 2 nanocomposite and the standard hexagonal phase of Se (JCPDS card no: 65-I876). (B and C) Medium- and high-magnification TEM images of $\mathrm{Se} @ \mathrm{SiO}_{2}$, showing that Se nanocrystals (diameter less than $5 \mathrm{~nm}$ ) are distributed in the $\mathrm{Se}_{\mathrm{SiO}} \mathrm{S}_{2}$ nanocomposite. (D) TEM image of the porous Se@SiO 2 nanocomposite. (E) The viability of SH-SY5Y cells treated with various concentrations of Se@SiO $\mathrm{S}_{2}$. The experiment was performed in triplicate and expressed as the mean \pm standard deviation. Differences between groups were analyzed using one-way ANOVA followed by Bonferroni's multiple comparisons. $* P<0.05$, $* * P<0.01$.

Abbreviations: XRD, X-ray diffractometer; TEM, transmission electron microscope.

the dosage of Se to guarantee beneficial effects and reduce toxicity. ${ }^{24,25}$

\section{Evaluation of the Toxicity of the Se@SiO 2 Nanocomposite in SH-SY5Y Cells}

Because Se has a narrow margin between beneficial and toxic effects, we evaluated the toxicity of $\mathrm{Se} @ \mathrm{SiO}_{2}$ in SH-SY5Y cells by CCK-8 assay. The results (Figure 1E) demonstrated that the SH-SY5Y cell viability decreased significantly when the
Se@ $\mathrm{SiO}_{2}$ concentration was $200 \mu \mathrm{g} / \mathrm{mL}$ and above. $\mathrm{Se} @ \mathrm{SiO}_{2}(100 \mu \mathrm{g} / \mathrm{mL})$ was chosen as the highest concentration for the following in vitro study.

\section{Se@SiO 2 Pretreatment Endowed SH-SY5Y Cells with Resistance to Hemin-Induced Toxicity}

To determine whether the $\mathrm{Se} @ \mathrm{SiO}_{2}$ nanocomposite can protect SH-SY5Y cells from hemin-induced toxicity, the cells were pretreated with various concentrations of 
$\mathrm{Se} @ \mathrm{SiO}_{2}$ for $12 \mathrm{~h}$ and then exposed to $25 \mu \mathrm{M}$ hemin. Cell apoptosis and cell viability were evaluated. Figure 2A shows the TUNEL staining of the treated cells. The apoptosis rate was quantitated by flow cytometry analysis (Figure 2B). The results (Figure 2C) revealed that the $100 \mu \mathrm{g} / \mathrm{mL} \mathrm{Se} @ \mathrm{SiO}_{2}$ treatment did not increase cell apoptosis, whereas $25 \mu \mathrm{M}$ hemin significantly increased the apoptosis rate $(P<0.01)$. Pretreatment with $25 \mu \mathrm{g} / \mathrm{mL} \quad \mathrm{Se} @ \mathrm{SiO}_{2} \quad(P<0.05)$ and $100 \mu \mathrm{g} / \mathrm{mL} \mathrm{Se} @ \mathrm{SiO}_{2}(P<0.01)$ significantly decreased

A

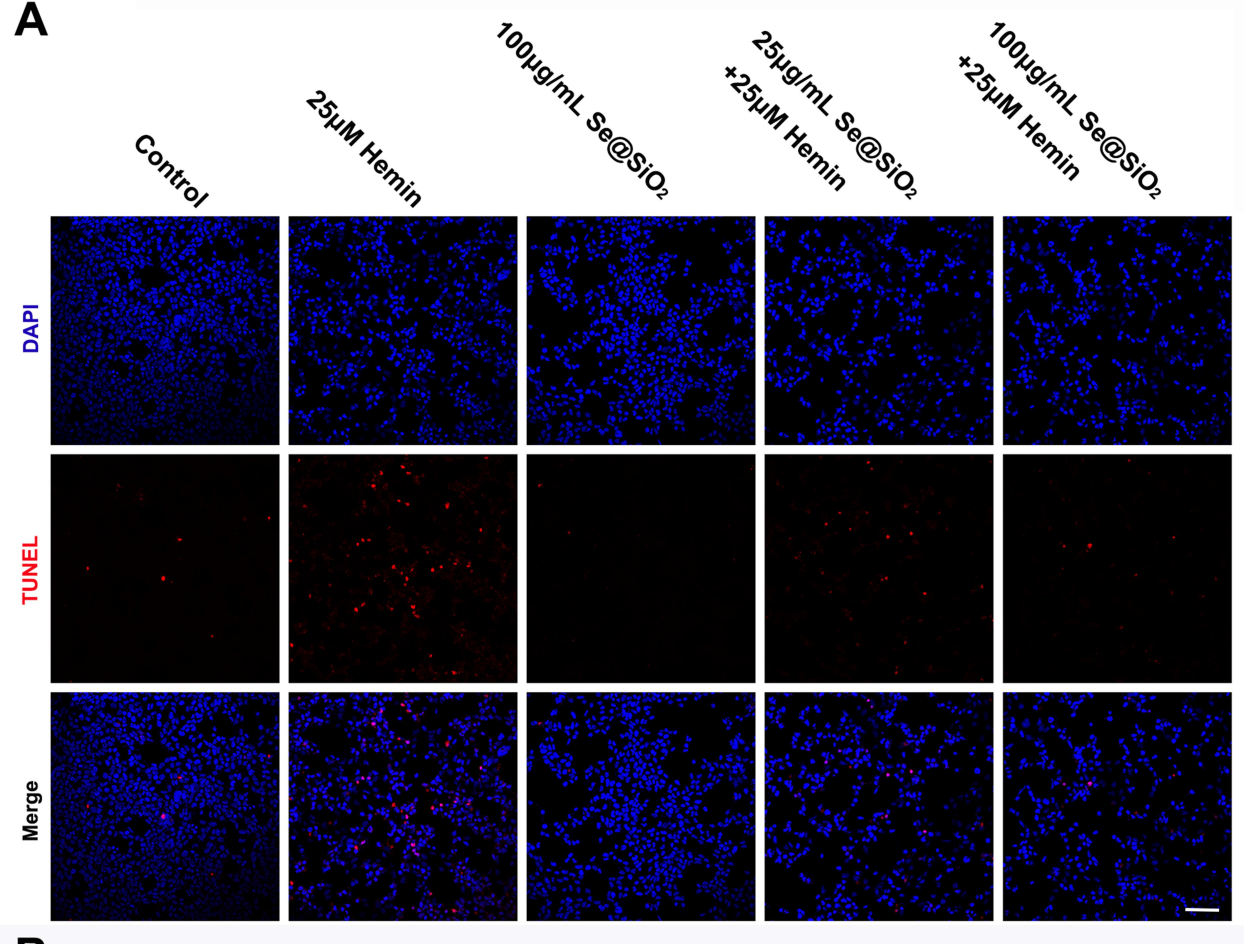

B

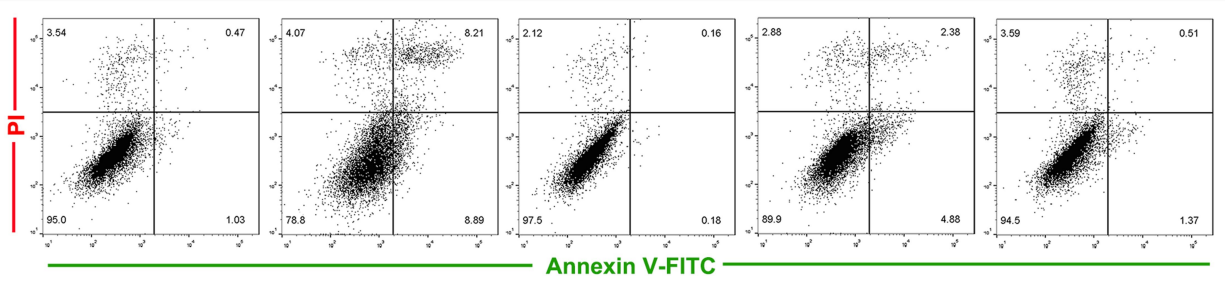

C

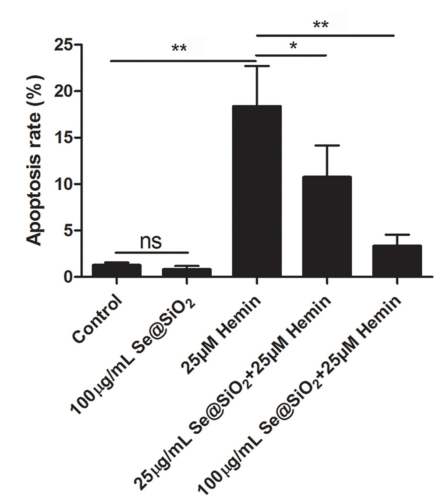

D

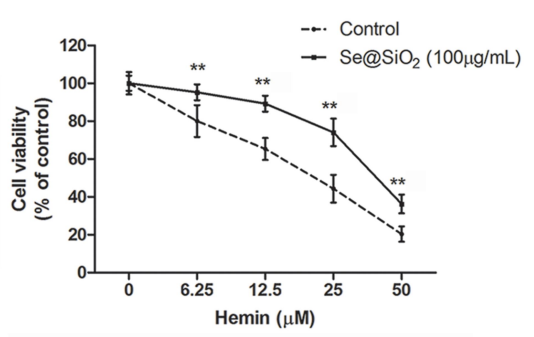

Figure 2 Effect of the $\mathrm{Se} @ \mathrm{SiO}_{2}$ nanocomposite on the resistance to hemin-induced toxicity in SH-SY5Y cells.

Notes: (A) TUNEL staining of treated SH-SY5Y cells. (B and C) Flow cytometry analysis of cell apoptosis. (D) The viability of SH-SY5Y cells pretreated with or without I00 $\mu \mathrm{g} / \mathrm{mL} \mathrm{Se@SiO} 2$ and exposed to various concentrations of hemin. All experiments were performed 3 times and expressed as the mean \pm standard deviation. Differences between groups were analyzed using one-way ANOVA followed by Bonferroni's multiple comparisons. $* P<0.05, * * P<0.01$. Bar $=100 \mu \mathrm{m}$.

Abbreviation: TUNEL, TdT-dUTP nick-end labeling. 
the cell apoptosis rate compared to hemin-treated cells. The CCK-8 assay (Figure 2D) demonstrated that the 100 $\mu \mathrm{g} / \mathrm{mL} \mathrm{Se} @ \mathrm{SiO}_{2}$ pretreatment endowed the cells with resistance to hemin-induced toxicity.

\section{$\mathrm{Se} @ \mathrm{SiO}_{2}$ Pretreatment Prevented Hemin-Induced Intracellular ROS}

\section{Accumulation}

Hemin is highly toxic due to the induction of ROS. To determine whether Se@SiO $\mathrm{Si}_{2}$ protects SH-SY5Y cells by reducing ROS accumulation, we detected intracellular ROS with DCFH-DA probes. Intracellular ROS were represented by green fluorescence under a fluorescence microscope (Figure 3A). The mean fluorescence intensity was quantitated by flow cytometry analysis (Figure 3B). The results showed that intracellular ROS were significantly increased after hemin insult $(P<0.01)$. Pretreatment with $25 \mu \mathrm{g} / \mathrm{mL}$ $\mathrm{Se} @ \mathrm{SiO}_{2}$ and $100 \mu \mathrm{g} / \mathrm{mL} \quad \mathrm{Se} @ \mathrm{SiO}_{2}$ dose-dependently decreased the intracellular ROS $(P<0.01)$.

\section{$\mathrm{Se} @ \mathrm{SiO}_{2}$ Treatment Improved ICH-Induced Neurological Deficits}

Neurological deficits were present in all ICH mice. Treatment with $1 \mathrm{mg} / \mathrm{kg} \mathrm{Se} @ \mathrm{SiO}_{2}$ significantly decreased the neurological deficit score $1 \mathrm{~d}(P<0.05)$ and $3 \mathrm{~d}(P<0.01)$ post ICH (Figure 4A). In the rotarod test (Figure 4B), significant improvement was observed in the $0.5 \mathrm{mg} / \mathrm{kg}$ $\mathrm{Se} @ \mathrm{SiO}_{2}$-treated group $1 \mathrm{~d}, 3 \mathrm{~d}$, and $5 \mathrm{~d}$ after ICH compared to the vehicle-treated group $(P<0.01)$. Significant improvement in the $1 \mathrm{mg} / \mathrm{kg} \mathrm{Se} @ \mathrm{SiO}_{2}$-treated group was observed at all the time points studied $(P<0.01)$. There was a trend in which $1 \mathrm{mg} / \mathrm{kg} \mathrm{Se} @ \mathrm{SiO}_{2}$-treated mice had a better performance compared to $0.5 \mathrm{mg} / \mathrm{kg} \mathrm{Se} @ \mathrm{SiO}_{2}$-treated mice, although no significant difference was obtained.

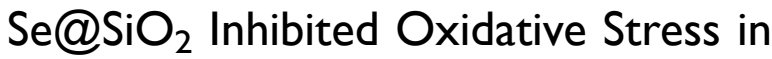 Perihematoma After ICH}

Oxidative stress contributes to secondary injury after ICH. In light of this, the expression of iNOS (an inducible
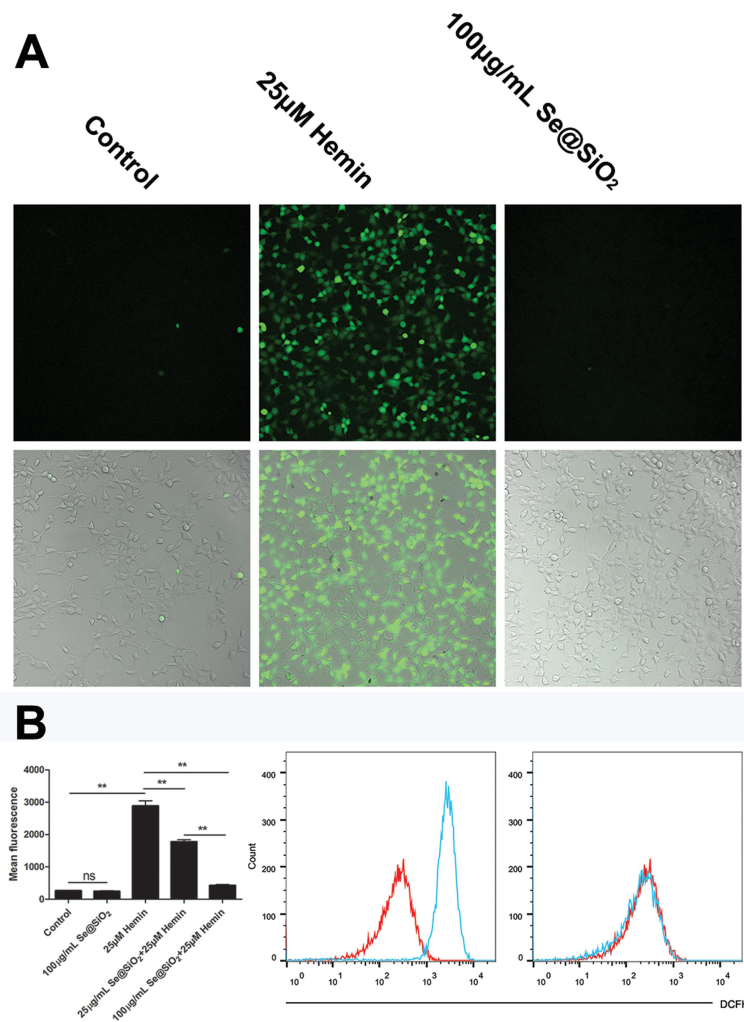
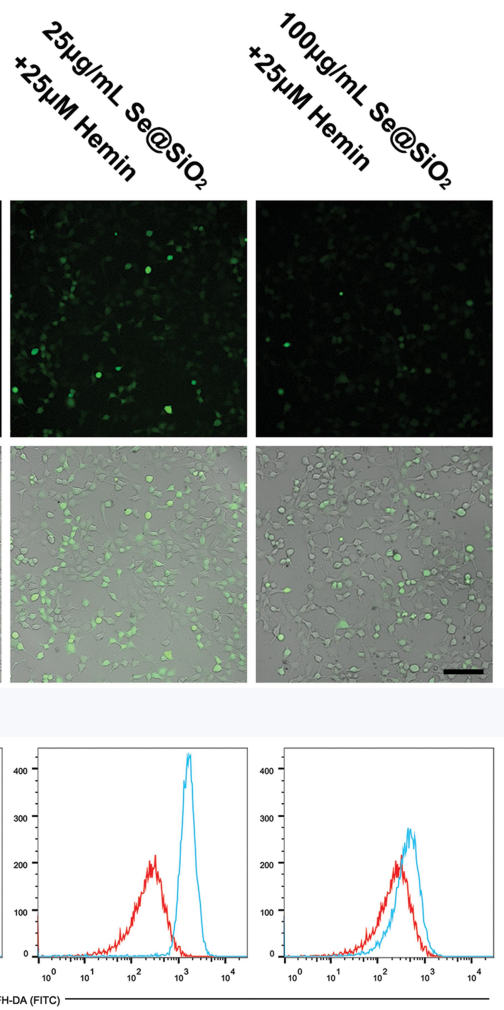

Figure 3 Effect of the $\mathrm{Se@SiO}$ nanocomposite on hemin-induced ROS accumulation in SH-SY5Y cells.

Notes: The treated cells were incubated with the ROS probe DCFH-DA. (A) Intracellular ROS are represented by green fluorescence under a fluorescence microscope. (B) The mean fluorescence intensity was quantitated by flow cytometry analysis. The overlaid histogram shows the shift of the fluorescence intensity (red for control and blue for treated samples). The mean fluorescence was plotted into a histogram $(n=3)$. Differences between groups were analyzed using one-way ANOVA followed by Bonferroni's multiple comparisons. ns: $P=0.9999, * * P<0.01$. Bar $=100 \mu \mathrm{m}$.

Abbreviation: ROS, reactive oxygen species. 
A

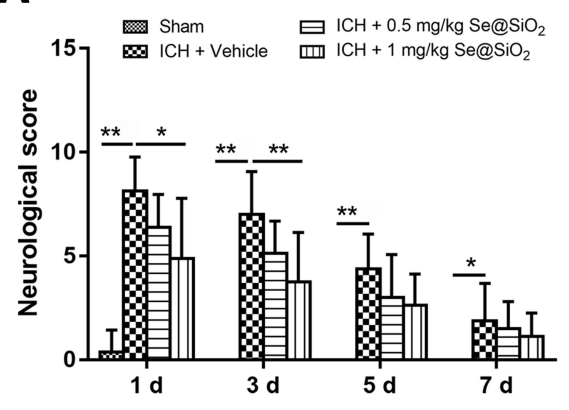

B

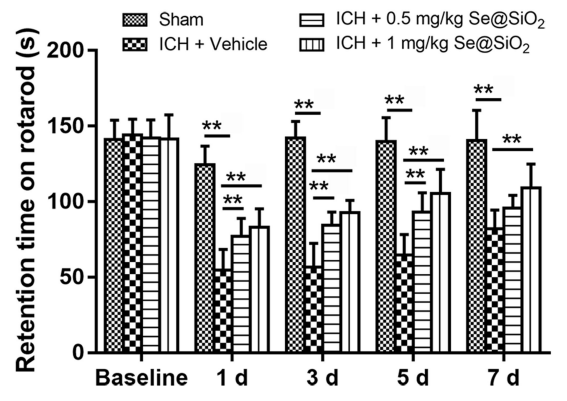

Figure 4 Behavioral test of the $\mathrm{ICH}$ mice treated with or without the $\mathrm{Se} @ \mathrm{SiO}_{2}$ nanocomposite.

Notes: (A) Total neurological score of sham-operated, ICH + vehicle-treated, ICH + 0.5 mg/kg Se@SiO after surgery. (B) Rotarod test of sham-operated, ICH + vehicle-treated, ICH + 0.5 mg/kg Se@SiO ${ }_{2}$-treated and ICH + I mg/kg Se@SiO surgery. $(n=8)$. Differences between groups were analyzed using one-way ANOVA followed by Bonferroni's multiple comparisons. $* P<0.05$, $* * P<0.01$.

Abbreviation: $\mathrm{ICH}$, intracerebral hemorrhage.

enzyme responsible for oxidative stress), the concentration of MDA (the product of lipid peroxidation) and the activity of GSH-Px (the key enzyme of the antioxidant defense system) were investigated $3 \mathrm{~d}$ after ICH to evaluate the role of $\mathrm{Se} @ \mathrm{SiO}_{2}$ in oxidative stress defense. As shown in Figure $5 \mathrm{~A}-\mathrm{C}$, the expression of iNOS and MDA
A

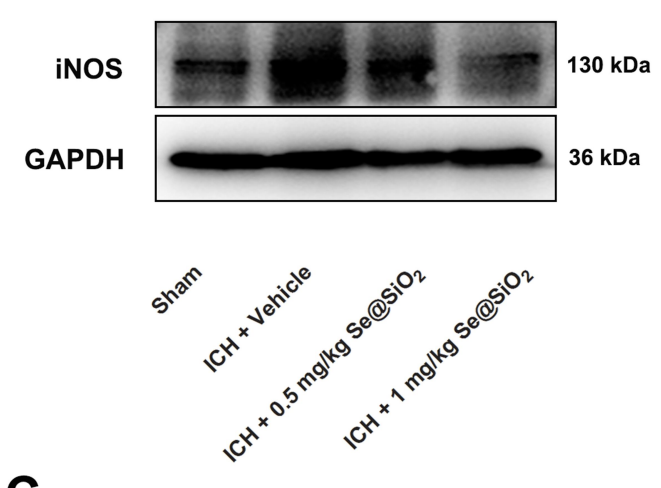

C

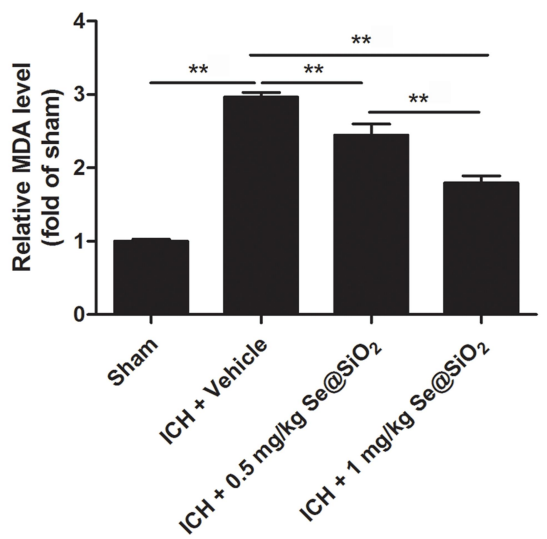

B

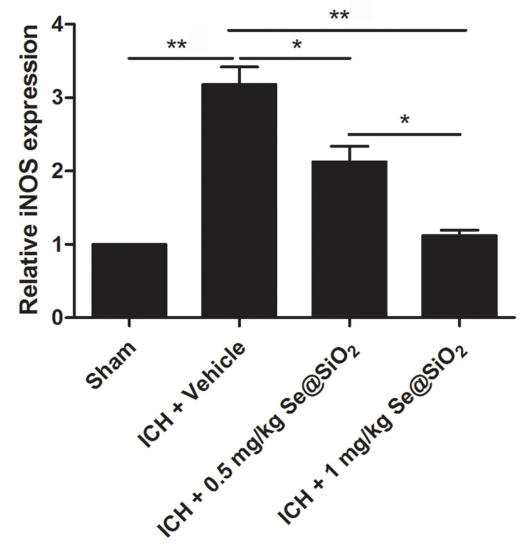

D

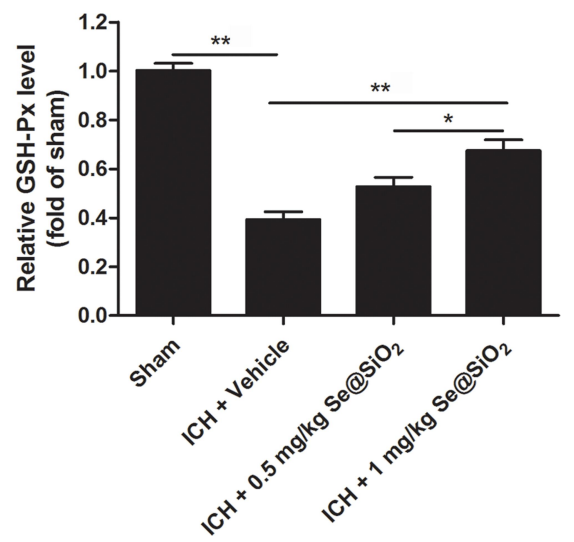

Figure 5 Effect of the $\mathrm{Se} @ \mathrm{SiO}_{2}$ nanocomposite on oxidative stress markers in ICH mice.

Notes: (A) Western blot analysis of iNOS expression in perihematomal tissues $3 \mathrm{~d}$ after surgery. (B) Densitometric analysis of the blots. ( $\mathrm{n}=3$ ). (C) Measurement of the MDA level $(n=8)$. (D) The activity of GSH-Px $(n=8)$. The results were normalized to the sham group and expressed as the mean \pm standard deviation. Differences between groups were analyzed using one-way ANOVA followed by Bonferroni's multiple comparisons. $* P<0.05$, $* * P<0.01$.

Abbreviations: $\mathrm{ICH}$, intracerebral hemorrhage; MDA, malonaldehyde; GSH-Px, glutathione peroxidase. 
production significantly increased in the vehicle-treated group compared to the sham group $(P<0.01)$. $\mathrm{Se} @ \mathrm{SiO}_{2}$ treatment dose-dependently suppressed iNOS expression and MDA production $(P<0.05)$. The GSH-Px activity in the vehicle-treated group significantly decreased compared to that in the sham group $(P<0.01)$, which was restored by $\mathrm{Se} @ \mathrm{SiO}_{2}$ treatment in a dose-dependent manner $(P<0.05)$ (Figure 5D).

\section{$\mathrm{Se} @ \mathrm{SiO}_{2}$ Protected BBB Integrity and Attenuated Brain Edema After ICH}

To assess the effect of $\mathrm{Se} @ \mathrm{SiO}_{2}$ on ICH-induced BBB disruption and brain edema, the expression of tight junction proteins (ZO-1, occludin) and aquaporin-4 (AQP4) within the perihematoma was quantitated by Western blot analysis. As shown (Figure 6A and B), cerebral edema and Evans blue extravasation were markedly increased $3 \mathrm{~d}$ after $\mathrm{ICH}$ $(P<0.001)$, and $\mathrm{Se} @ \mathrm{SiO}_{2}$ administration alleviated cerebral edema and Evans blue extravasation in a dose-dependent manner $(P<0.05)$. Western blot analysis revealed that AQP4 expression significantly increased $3 \mathrm{~d}$ after ICH $(P<0.05)$, and $1 \mathrm{mg} / \mathrm{kg} \mathrm{Se} @ \mathrm{SiO}_{2}$ administration significantly attenuated the elevation in AQP4 expression $(P<0.01)$ (Figure 6C and $\mathrm{D})$. The expression of the tight junction proteins $\mathrm{ZO}-1$ and occludin was suppressed significantly after ICH $(P<0.01)$, and 0.5 and $1 \mathrm{mg} / \mathrm{kg} \mathrm{Se} @ \mathrm{SiO}_{2}$ treatment restored their expression $(P<0.01)$ (Figure $6 \mathrm{E}$ and $\mathrm{F})$. However, no statistical significance was observed in $\mathrm{ZO}-1$ and occludin expression between the 0.5 and $1 \mathrm{mg} / \mathrm{kg} \mathrm{Se} @ \mathrm{SiO}_{2}$-treated groups.

\section{$\mathrm{Se} @ \mathrm{SiO}_{2}$ Protected Cells from Apoptosis After $\mathrm{ICH}$}

TUNEL staining (Figure 7A and B) showed that apoptotic cells were significantly more abundant in the vehicletreated group than in the sham group $(P<0.001)$. $\mathrm{Se} @ \mathrm{SiO}_{2}$ treatment decreased the apoptosis rate in a dosedependent manner $(P<0.01)$.

Western blot analysis of the proapoptotic and antiapoptotic proteins demonstrated that $\mathrm{Bcl}-2$ and the ratio of Bcl2/Bax significantly decreased in the vehicle-treated group compared to the sham group $(P<0.001)$. The decrease was counteracted by the $\mathrm{Se} @ \mathrm{SiO}_{2}$ treatment (Figure 8A-C). The expression of Bax and cleaved caspase 3 and the ratio of cleaved caspase 3/caspase 3 significantly increased in the vehicle-treated group compared to the sham group $(P<0.05) . \quad \mathrm{Se} @ \mathrm{SiO}_{2} \quad$ treatment attenuated the elevation of the expression of these proapoptotic proteins $(P<0.01)$ (Figure 8D-F).

\section{Discussion}

Intracerebral hemorrhage is a severe neurological crisis associated with high mortality and morbidity. Oxidative stress-induced cell apoptosis, brain edema and BBB disruption contribute to neurological deterioration after the primary injury of $\mathrm{ICH}^{29,30}$ Hence, antioxidative approaches have been proven to be neuroprotective.

Autologous blood injection and collagenase-induced ICH mouse models are two commonly used models. Autologous blood injection models lack potential vascular pathological changes. The hematoma volume is unstable due to the backflow and diffusion of the injected blood along the needle tract and corpus callosum. In addition, donor blood or anticoagulants may potentially affect inflammation and the complement or coagulation system. The collagenase-induced ICH model is easy to establish and can simulate acute cerebrovascular injury, causing spontaneous bleeding, and the hematoma gradually progresses within $4-5$ h. ${ }^{31}$ This model can better simulate the progress of clinical patients because $14-20 \%$ of $\mathrm{ICH}$ patients have persistent bleeding, and $17 \%$ of patients have bleeding for more than $6 \mathrm{~h}^{32,33}$ In addition, the localization and volume of the hematoma in this model are relatively consistent, with good reproducibility. In this study, we identified the neuroprotective effect of the $\mathrm{Se} @ \mathrm{SiO}_{2}$ nanocomposite in a collagenase-induced ICH mouse model. Briefly, Se@, $\mathrm{SiO}_{2}$ treatment attenuated oxidative injury, inhibited cell apoptosis, protected BBB integrity, alleviated brain edema and improved neurological function in ICH mice. In vitro, $\mathrm{Se} @ \mathrm{SiO}_{2}$ protected $\mathrm{SH}-$ SY5Y cells from hemin-induced apoptosis by preventing intracellular ROS accumulation.

$\mathrm{Se} @ \mathrm{SiO}_{2}$ is a novel porous $\mathrm{SiO}_{2}$-coated ultrasmall Se particle fabricated by Liu et al. The porous structure endows the $\mathrm{Se} @ \mathrm{SiO}_{2}$ nanocomposite with multiple functions. ${ }^{24}$ When materials are engineered into nanoparticles, they acquire unique properties, which may increase their penetration into the central nervous system. ${ }^{34}$ In this study, we verified that $\mathrm{Se} @ \mathrm{SiO}_{2}$ nanoparticles had good BBB penetration. Moreover, the Se concentration seemed to be higher in the ICH brain than in the control brain (although no significant difference was found), which may be related to the BBB disruption induced by ICH. In this study, we found that cell apoptosis was inhibited and neurological function was improved by $\mathrm{Se} @ \mathrm{SiO}_{2}$ administration in ICH mice. 
A

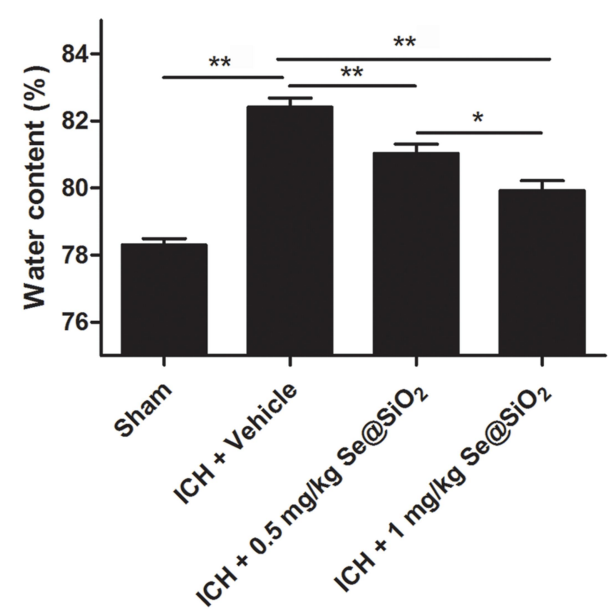

C

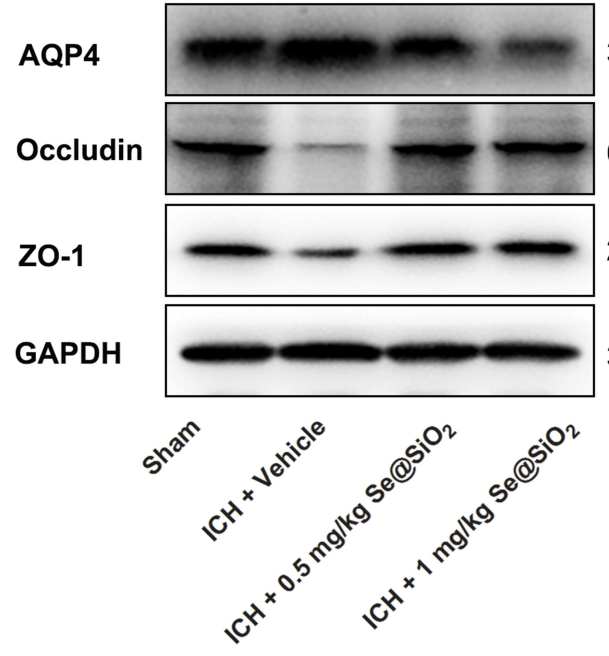

E

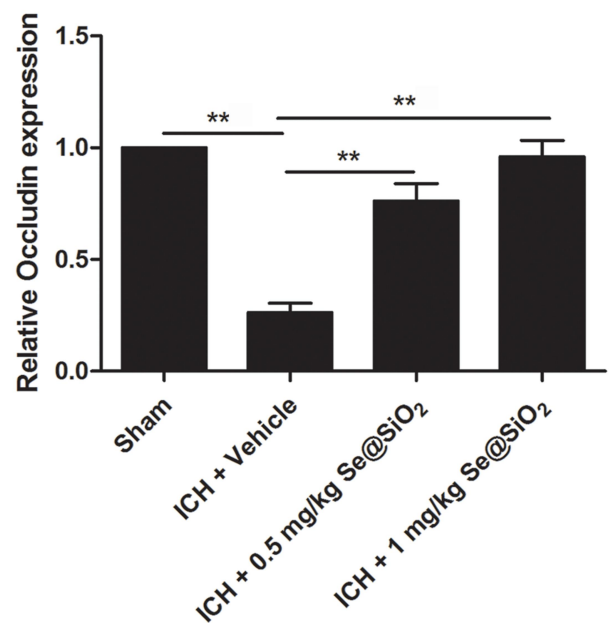

B

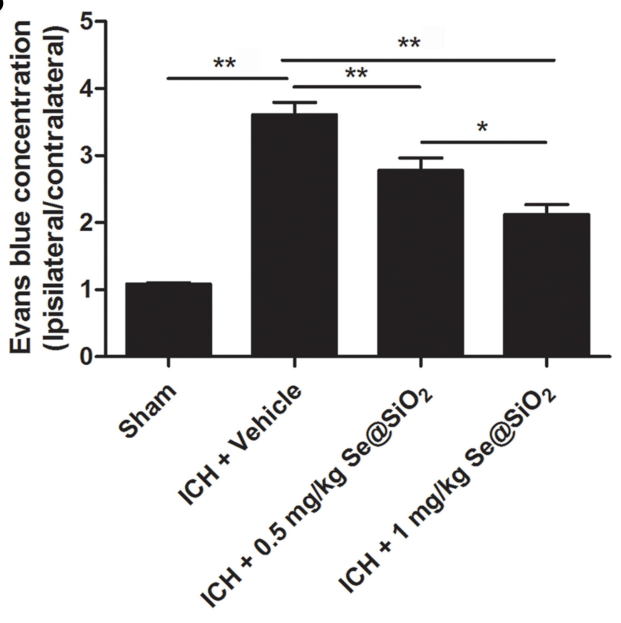

D

34 kDa

60 kDa

220 kDa

$36 \mathrm{kDa}$

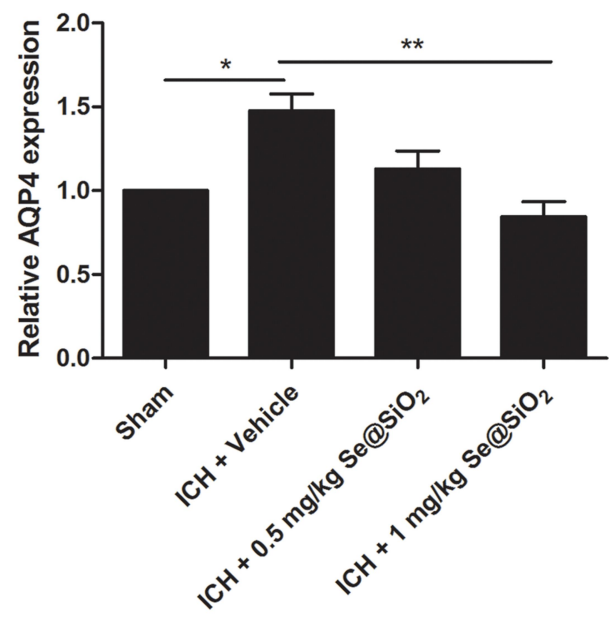

$\mathbf{F}$

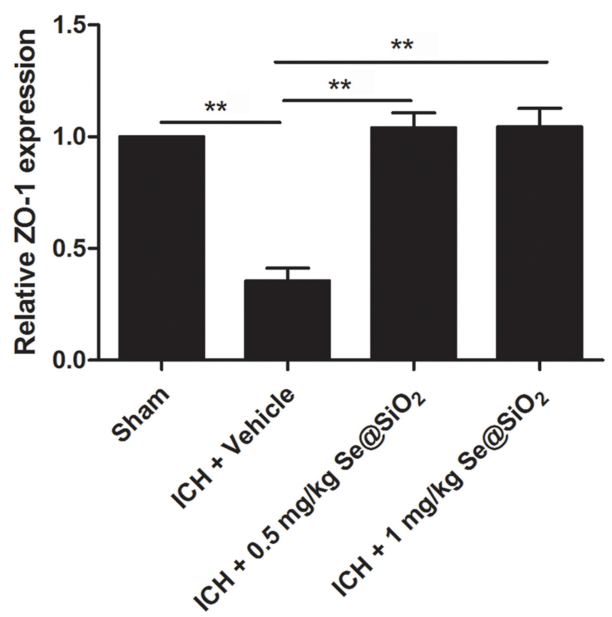

Figure 6 Effect of the $\mathrm{Se} @ \mathrm{SiO}_{2}$ nanocomposite on brain edema and BBB disruption in ICH mice.

Notes: (A) Water content of the brain tissue $3 \mathrm{~d}$ after surgery $(n=8)$. (B) Evans blue concentration in the brain tissue $3 \mathrm{~d}$ after surgery $(\mathrm{n}=8)$. The results are expressed as the ipsilateral/contralateral ratio. (C) Western blot analysis of AQP4, occludin and ZO-I expression in perihematomal tissues $3 \mathrm{~d}$ after surgery. (D) Densitometric analysis of the blots of AQP4 $(n=3)$. (E) Densitometric analysis of occludin blots $(n=3)$. (F) Densitometric analysis of the blots of ZO-I ( $n=3)$. Differences between groups were analyzed using one-way ANOVA followed by Bonferroni's multiple comparisons. $* P<0.05$, $* * P<0.01$.

Abbreviations: BBB, blood-brain barrier; ICH, intracerebral hemorrhage; AQP4, aquaporin-4; ZO-I, zonula occludens-I. 
A

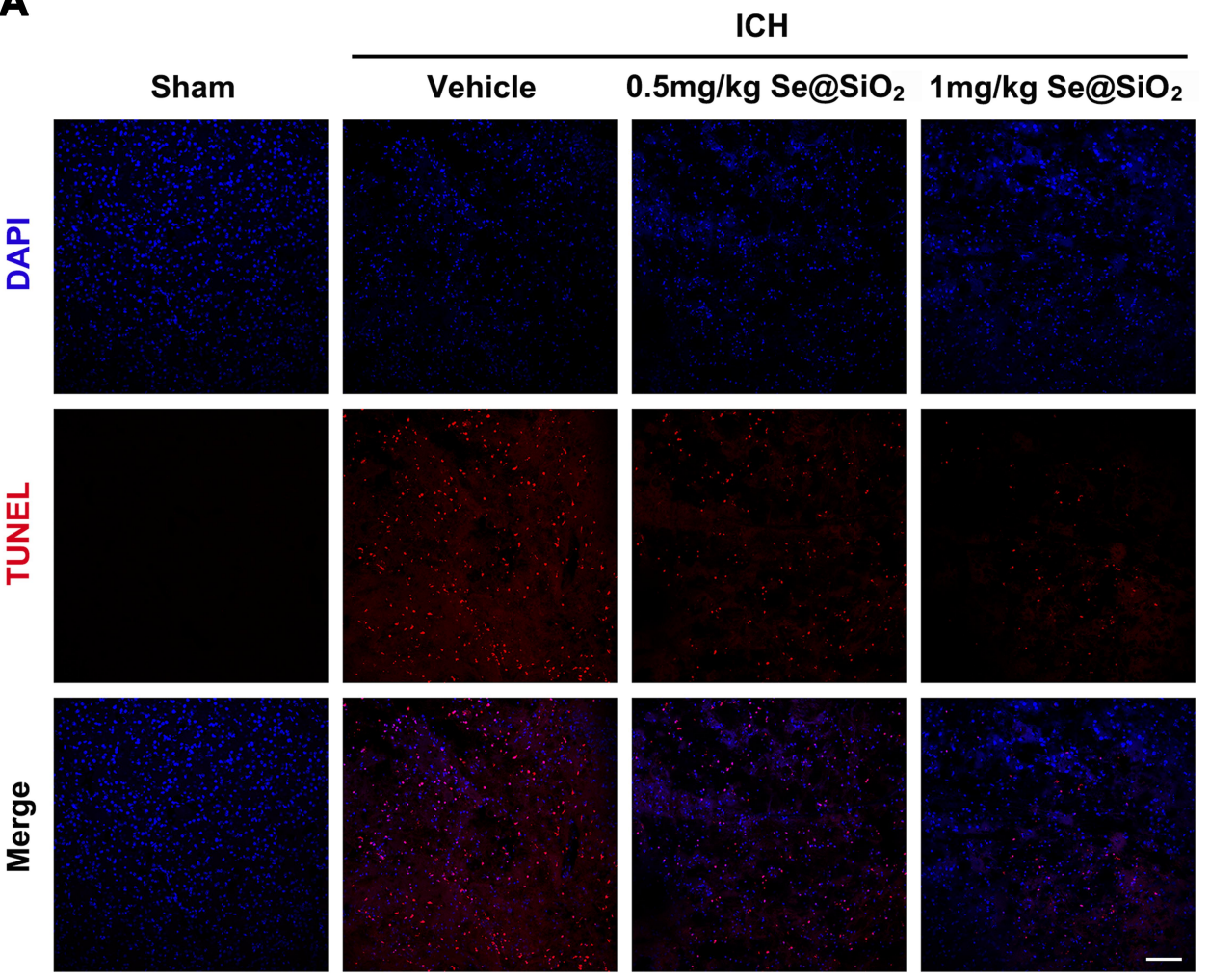

B

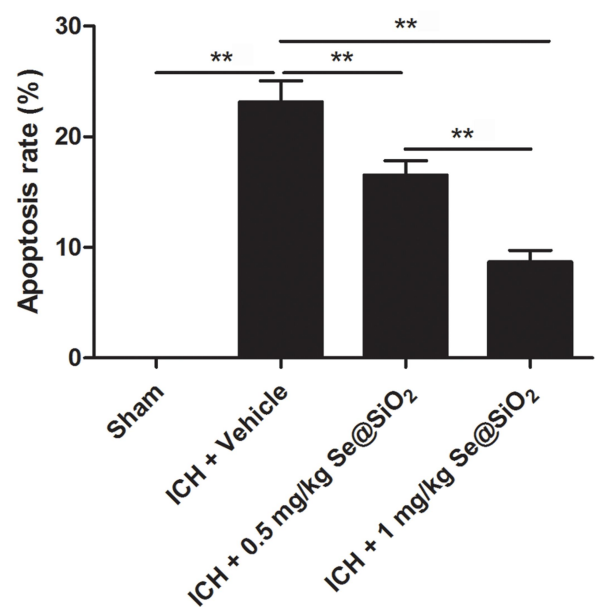

Figure 7 Effect of the $\mathrm{Se} @ \mathrm{SiO}_{2}$ nanocomposite on perihematomal cell apoptosis in ICH mice.

Notes: (A) TUNEL staining of perihematomal brain slices from sham-operated, ICH + vehicle-treated, ICH + 0.5 mg/kg Se@SiO treated mice $3 \mathrm{~d}$ after surgery. (B) The proportion of apoptotic cells was calculated and plotted into a histogram $(n=8)$. Differences between groups were analyzed using one-way ANOVA followed by Bonferroni's multiple comparisons. $* * P<0.01$. Bar $=100 \mu \mathrm{m}$.

Abbreviations: ICH, intracerebral hemorrhage; TUNEL, TdT-dUTP nick-end labeling.

The process of cell apoptosis is regulated by the expression of the antiapoptotic Bcl-2 protein and the proapoptotic Bax protein $^{35}$ and is executed by cleaved caspase $3 .{ }^{36}$ Western blot analysis revealed that $\mathrm{ICH}$-induced perihematomal upregulation of the ratio of $\mathrm{Bax} / \mathrm{Bcl}-2$ and cleaved caspase 3/caspase 3 was attenuated by $\mathrm{Se} @ \mathrm{SiO}_{2}$. This was consistent with the TUNEL staining results.
Oxidative stress is one of the main causes of apoptosis following $\mathrm{ICH}$. Excessive ferrous iron liberated from hemin degradation catalyzes the production of large amounts of hydroxyl radicals, which lead to lipid peroxidation and cell apoptosis. ${ }^{6}$ Oxidative stress results from the imbalance between ROS production and anti-oxidation capacity. Our results indicated that the activity of GSH-Px, 
B

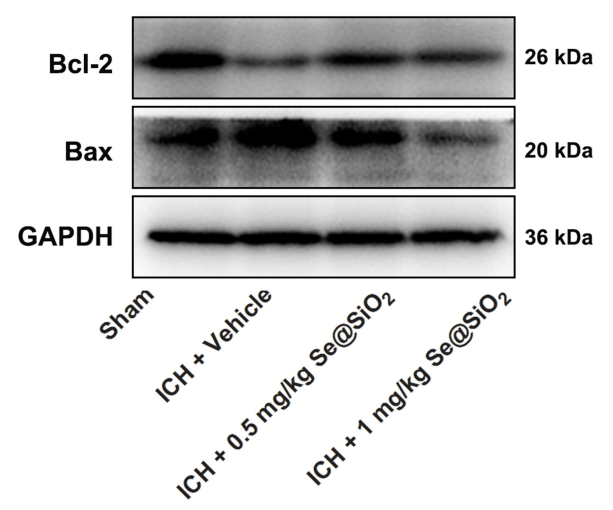

B

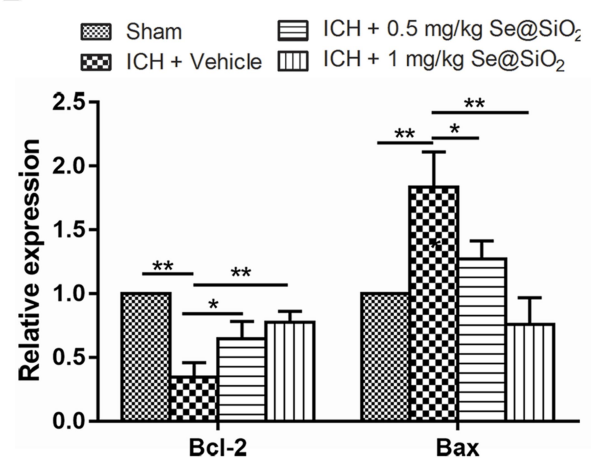

C

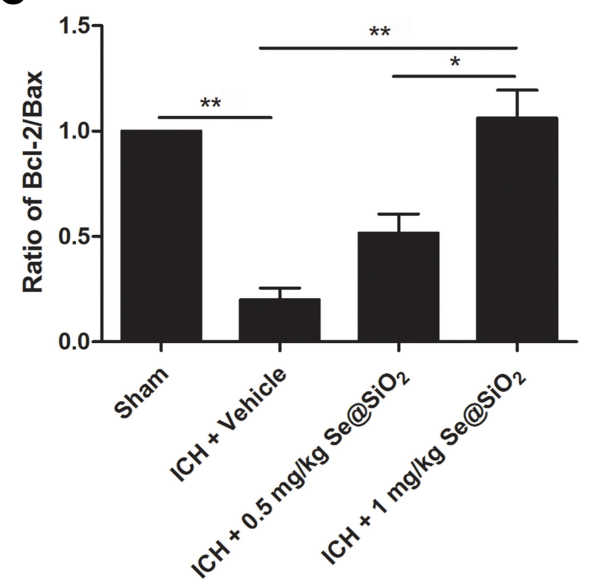

D

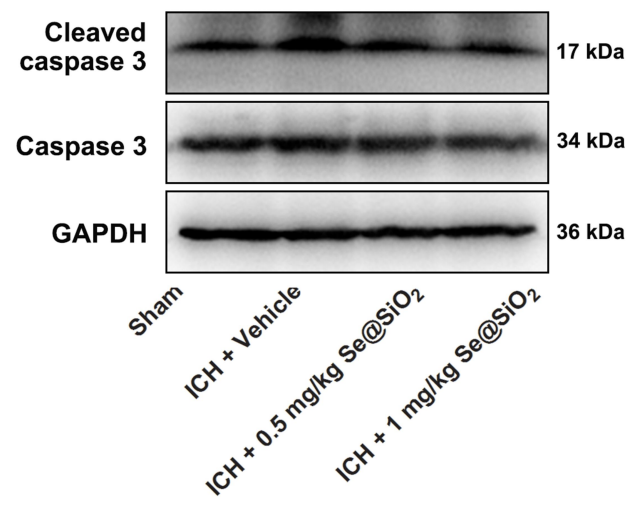

E $\mathrm{Sham}_{\mathrm{ICH}+\text { Vehicle }} \mathrm{I} \mathrm{ICH}+0.5 \mathrm{mg} / \mathrm{kg} \mathrm{Se} @ \mathrm{SiO}_{2}$
$\mathrm{ICH}+1 \mathrm{mg} / \mathrm{kg} \mathrm{Se} @ \mathrm{SiO}_{2}$

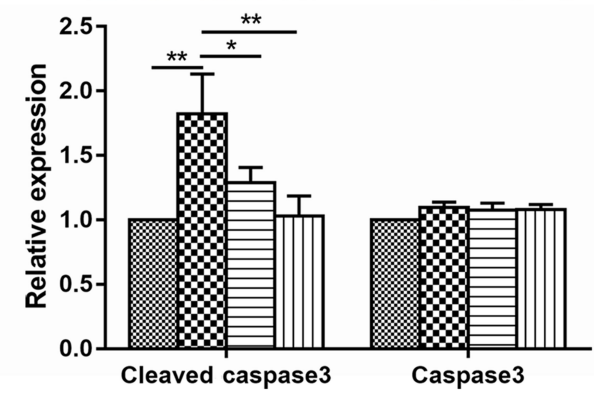

F

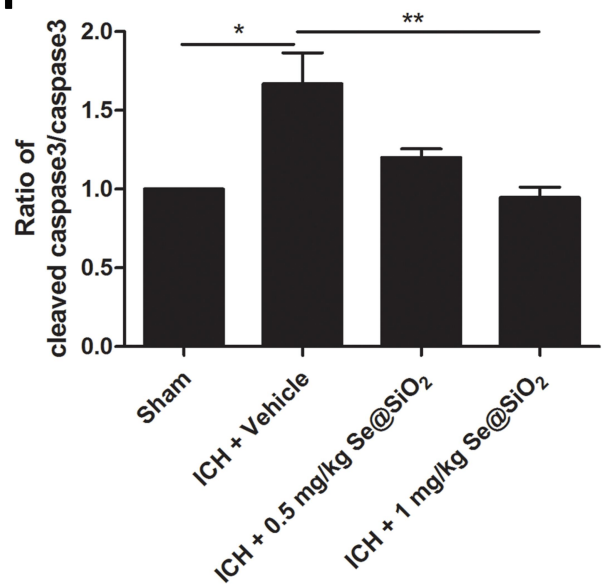

Figure 8 Effect of the $\mathrm{Se} @ \mathrm{SiO}_{2}$ nanocomposite on proapoptotic and antiapoptotic protein expression in the perihematomal tissue of ICH mice.

Notes: (A) Western blot analysis of Bcl-2 and Bax expression in perihematomal tissues $3 \mathrm{~d}$ after surgery. (B) Densitometric analysis of the blots of Bcl-2 and Bax. (C) The ratio of $\mathrm{Bcl}-2 / \mathrm{Bax}$. (D) Western blot analysis of cleaved caspase 3 and caspase 3 expression in perihematomal tissues $3 \mathrm{~d}$ after surgery. (E) Densitometric analysis of the blots of cleaved caspase 3 and caspase 3. (F) The ratio of cleaved caspase 3/caspase 3 . The results were normalized to the sham group and expressed as the mean \pm standard deviation $(n=3)$. Differences between groups were analyzed using one-way ANOVA followed by Bonferroni's multiple comparisons. $* P<0.05$, $* * P<0.0$ I.

Abbreviation: $\mathrm{ICH}$, intracerebral hemorrhage.

which is a selenium-containing enzyme responsible for ROS scavenging, was significantly increased by $\mathrm{Se} @ \mathrm{SiO}_{2}$ treatment. Consequently, the product of lipid peroxidation decreased. An in vitro study demonstrated that $\mathrm{Se} @ \mathrm{SiO}_{2}$ pretreatment reduced intracellular ROS in a dose-dependent manner. Our results confirmed that
$\mathrm{Se} @ \mathrm{SiO}_{2}$ protected the cells from apoptosis by increasing GSH-Px activity and scavenging ROS.

Brain edema following ICH contributes to increased intracranial pressure and neurological dysfunction. The severity of edema is positively correlated with a poor prognosis. ${ }^{37}$ Perihematomal edema develops immediately 
after $\mathrm{ICH}$, peaking on the third day in experimental $\mathrm{ICH}$ models. ${ }^{38}$ In our study, $3 \mathrm{~d}$ post-ICH was selected as a time point for the water content and BBB permeability evaluation.

Cytotoxic edema and vasogenic edema are the two major types of cerebral edema in the pathological process of ICH. Aquaporin-4 (AQP4), which is the most abundant water channel expressed in the endfeet of astrocytes, plays a key role in cytotoxic brain edema. ${ }^{39}$ It has been well documented that upregulation of AQP4 increases the amount of brain edema. ${ }^{40,41}$ Our data showed that AQP4 expression was upregulated on the 3rd day after ICH, which was attenuated by $\mathrm{Se} @ \mathrm{SiO}_{2}$ administration. This was in accordance with the changes in the brain water content. Vasogenic edema is caused by BBB disruption resulting from endothelial and neuroglial dysfunction. ${ }^{42}$ The tight junction proteins ZO-1 and occludin are critical for maintaining the integrity of the BBB. ${ }^{43,44}$ We found that $\mathrm{Se} @ \mathrm{SiO}_{2}$ treatment restored ZO-1 and occludin expression and reduced the extravasation of Evans blue after ICH. Our results demonstrated that $\mathrm{Se} @ \mathrm{SiO}_{2}$ markedly alleviated brain edema and protected BBB integrity. This phenomenon might be due to the antioxidant effect of $\mathrm{Se} @ \mathrm{SiO}_{2}$, which consequently protected the function of endothelial and neuroglial cells. We also investigated the Se concentration in the cortex, striatum, hippocampus and cerebellum, and no significant difference was found between these regions. Therefore, we propose that $\mathrm{Se} @ \mathrm{SiO}_{2}$ exerts neuroprotection in the context of $\mathrm{ICH}$ by increasing GSH-Px activity and scavenging ROS in multiple cell types (eg, neurons, astrocytes and endothelium etc.).

\section{Conclusion}

Our work demonstrated that the porous $\mathrm{Se} @ \mathrm{SiO}_{2}$ nanocomposite significantly improved neurological function by protecting the cells from ROS toxicity, attenuating brain edema and ameliorating BBB disruption. The porous $\mathrm{Se} @ \mathrm{SiO}_{2}$ nanocomposite is a promising anti-oxidative agent and has the potential to be employed for the clinical treatment of $\mathrm{ICH}$ and oxidative stress-related brain damage.

\section{Acknowledgments}

This work was financially supported by National Natural Science Foundation of China (No. 81901250, 81771318 and 81671194), Natural Science Foundation of Guangdong Province (No.2019A1515010104), High-level Hospital Construction Project of Guangdong Provincial People's
Hospital (No. DFJH201924) and Ph.D. Research Start-up Fund of Guangdong Provincial People's Hospital (No. 2018bq05).

\section{Disclosure}

The authors declare no conflicts of interest for this work.

\section{References}

1. Mracsko E, Veltkamp R. Neuroinflammation after intracerebral hemorrhage. Front Cell Neurosci. 2014;8:388. doi:10.3389/ fncel.2014.00388

2. Duan X, Wen Z, Shen H, Shen M, Chen G. Intracerebral hemorrhage, oxidative stress, and antioxidant therapy. Oxid Med Cell Longev. 2016;2016:1203285. doi:10.1155/2016/1203285

3. Hu X, Tao C, Gan Q, Zheng J, Li H, You C. Oxidative stress in intracerebral hemorrhage: sources, mechanisms, and therapeutic targets. Oxid Med Cell Longev. 2016;2016:3215391. doi:10.1155/ 2016/3215391

4. Qu J, Chen W, Hu R, Feng H. The injury and therapy of reactive oxygen species in intracerebral hemorrhage looking at mitochondria. Oxid Med Cell Longev. 2016;2016:2592935. doi:10.1155/2016/ 2592935

5. Seiwert N, Wecklein S, Demuth P, et al. Heme oxygenase 1 protects human colonocytes against ROS formation, oxidative DNA damage and cytotoxicity induced by heme iron, but not inorganic iron. Cell Death Dis. 2020;11(9):787. doi:10.1038/s41419-020-02950-8

6. Yang Y, Xi Z, Xue Y, et al. Hemoglobin pretreatment endows rat cortical astrocytes resistance to hemin-induced toxicity via $\mathrm{Nrf} 2 /$ HO-1 pathway. Exp Cell Res. 2017;361(2):217-224. doi:10.1016/j. yexcr.2017.10.020

7. Sun Y, Dai M, Wang Y, et al. Neuroprotection and sensorimotor functional improvement by curcumin after intracerebral hemorrhage in mice. $J$ Neurotrauma. 2011;28(12):2513-2521. doi:10.1089/ neu.2011.1958

8. Wang BF, Cui ZW, Zhong ZH, et al. Curcumin attenuates brain edema in mice with intracerebral hemorrhage through inhibition of AQP4 and AQP9 expression. Acta Pharmacol Sin. 2015;36 (8):939-948. doi:10.1038/aps.2015.47

9. Wei N, Wei Y, Li B, Pang L. Baicalein promotes neuronal and behavioral recovery after intracerebral hemorrhage via suppressing apoptosis, oxidative stress and neuroinflammation. Neurochem Res. 2017;42(5):1345-1353. doi:10.1007/s11064-017-2179-y

10. Xie RX, Li DW, Liu XC, et al. Carnosine attenuates brain oxidative stress and apoptosis after intracerebral hemorrhage in rats. Neurochem Res. 2017;42(2):541-551. doi:10.1007/s11064-016-2104-9

11. Kang D-W, Kim CK, Jeong H-G, et al. Biocompatible custom ceria nanoparticles against reactive oxygen species resolve acute inflammatory reaction after intracerebral hemorrhage. Nano Res. 2017;10 (8):2743-2760. doi:10.1007/s12274-017-1478-6

12. Bao Q, Hu P, Xu Y, et al. Simultaneous blood-brain barrier crossing and protection for stroke treatment based on edaravone-loaded ceria nanoparticles. ACS Nano. 2018;12(7):6794-6805. doi:10.1021/ acsnano.8b01994

13. Zachara BA. Selenium and selenium-dependent antioxidants in chronic kidney disease. Adv Clin Chem. 2015;68:131-151.

14. Zhai X, Zhang C, Zhao G, Stoll S, Ren F, Leng X. Antioxidant capacities of the selenium nanoparticles stabilized by chitosan. J Nanobiotechnology. 2017;15(1):4. doi:10.1186/s12951-016-0243-4

15. Estevez H, Garcia-Lidon JC, Luque-Garcia JL, Camara C. Effects of chitosan-stabilized selenium nanoparticles on cell proliferation, apoptosis and cell cycle pattern in HepG2 cells: comparison with other selenospecies. Colloids Surf B Biointerfaces. 2014;122:184-193. doi:10.1016/j.colsurfb.2014.06.062 
16. He Y, Chen S, Liu Z, Cheng C, Li H, Wang M. Toxicity of selenium nanoparticles in male sprague-dawley rats at supranutritional and nonlethal levels. Life Sci. 2014;115(1-2):44-51. doi:10.1016/j. lfs.2014.08.023

17. Peng D, Zhang J, Liu Q, Taylor EW. Size effect of elemental selenium nanoparticles (Nano-Se) at supranutritional levels on selenium accumulation and glutathione S-transferase activity. J Inorg Biochem. 2007;101(10):1457-1463. doi:10.1016/j.jinorgbio.2007.06.021

18. Liang T, Qiu X, Ye X, et al. Biosynthesis of selenium nanoparticles and their effect on changes in urinary nanocrystallites in calcium oxalate stone formation. 3 Biotech. 2020;10(1):23. doi:10.1007/ s13205-019-1999-7

19. Maddinedi SB, Mandal BK, Anna KK. Environment friendly approach for size controllable synthesis of biocompatible Silver nanoparticles using diastase. Environ Toxicol Pharmacol. 2017;49:131-136. doi:10.1016/j.etap.2016.11.019

20. Maddinedi SB, Mandal BK, Maddili SK. Biofabrication of size controllable silver nanoparticles - a green approach. $J$ Photochem Photobiol B. 2017;167:236-241. doi:10.1016/j.jphotobiol.2017. 01.003

21. Maddinedi SB, Mandal BK, Patil SH, Andhalkar VV, Ranjan S, Dasgupta N. Diastase induced green synthesis of bilayered reduced graphene oxide and its decoration with gold nanoparticles. J Photochem Photobiol B. 2017;166:252-258. doi:10.1016/j. jphotobiol.2016.12.008

22. Maddinedi S, Mandal BK, Ranjan S, Dasgupta N. Diastase assisted green synthesis of size-controllable gold nanoparticles. RSC $A d v$. 2015;5(34):26727-26733. doi:10.1039/C5RA03117F

23. Maddinedi SB, Sonamuthu J, Suzu KYS, et al. Silk sericin induced fabrication of reduced graphene oxide and its in-vitro cytotoxicity, photothermal evaluation. $J$ Photochem Photobiol $B$. 2018;186:189-196. doi:10.1016/j.jphotobiol.2018.07.020

24. Liu X, Deng G, Wang Y, et al. A novel and facile synthesis of porous $\mathrm{SiO} 2$-coated ultrasmall Se particles as a drug delivery nanoplatform for efficient synergistic treatment of cancer cells. Nanoscale. 2016;8 (16):8536-8541. doi:10.1039/C6NR02298G

25. Deng G, Niu K, Zhou F, et al. Treatment of steroid-induced osteonecrosis of the femoral head using porous Se@SiO2 nanocomposites to suppress reactive oxygen species. Sci Rep. 2017;7(1):43914. doi:10.1038/srep43914

26. Shi W, Hass B, Kuss MA, et al. Fabrication of versatile dynamic hyaluronic acid-based hydrogels. Carbohydr Polym. 2020;233:115803. doi:10.1016/j.carbpol.2019.115803

27. Lei B, Sheng $\mathrm{H}$, Wang $\mathrm{H}$, et al. Intrastriatal injection of autologous blood or clostridial collagenase as murine models of intracerebral hemorrhage. J Vis Exp. 2014;(89):89. doi:10.3791/51439

28. Zeng LL, He XS, Liu JR, Zheng CB, Wang YT, Yang GY. Lentivirusmediated overexpression of MicroRNA-210 improves long-term outcomes after focal cerebral ischemia in mice. CNS Neurosci Ther. 2016;22(12):961-969. doi:10.1111/cns.12589

29. Crack PJ, Taylor JM. Reactive oxygen species and the modulation of stroke. Free Radic Biol Med. 2005;38(11):1433-1444. doi:10.1016/j. freeradbiomed.2005.01.019

International Journal of Nanomedicine

\section{Publish your work in this journal}

The International Journal of Nanomedicine is an international, peerreviewed journal focusing on the application of nanotechnology in diagnostics, therapeutics, and drug delivery systems throughout the biomedical field. This journal is indexed on PubMed Central, MedLine, CAS, SciSearch ${ }^{\mathbb{R}}$, Current Contents ${ }^{\mathbb{R}} /$ Clinical Medicine, $^{2}$
30. Aronowski J, Hall CE. New horizons for primary intracerebral hemorrhage treatment: experience from preclinical studies. Neurol Res. 2005;27(3):268-279. doi:10.1179/016164105X25225

31. Wang J, Dore S. Heme oxygenase-1 exacerbates early brain injury after intracerebral haemorrhage. Brain. 2007;130(Pt 6):1643-1652. doi:10.1093/brain/awm095

32. Brott T, Broderick J, Kothari R, et al. Early hemorrhage growth in patients with intracerebral hemorrhage. Stroke. 1997;28(1):1-5. doi:10.1161/01.STR.28.1.1

33. Kazui S, Naritomi H, Yamamoto H, Sawada T, Yamaguchi $T$. Enlargement of spontaneous intracerebral hemorrhage. Incidence and time course. Stroke. 1996;27(10):1783-1787. doi:10.1161/01. STR.27.10.1783

34. Moura RP, Almeida A, Sarmento B. The role of non-endothelial cells on the penetration of nanoparticles through the blood brain barrier. Prog Neurobiol. 2017;159:39-49. doi:10.1016/j.pneurobio.2017.0 9.001

35. Kang R, Tang D, Lotze MT, Zeh HJ 3rd. RAGE regulates autophagy and apoptosis following oxidative injury. Autophagy. 2011;7 (4):442-444. doi:10.4161/auto.7.4.14681

36. Abu-Qare AW, Abou-Donia MB. Biomarkers of apoptosis: release of cytochrome c, activation of caspase-3, induction of 8-hydroxy-2'deoxyguanosine, increased 3-nitrotyrosine, and alteration of p53 gene. J Toxicol Environ Health B Crit Rev. 2001;4(3):313-332. doi:10.1080/109374001301419737

37. Jo K, Bajgur SS, Kim H, Choi HA, Huh PW, Lee K. A simple prediction score system for malignant brain edema progression in large hemispheric infarction. PLoS One. 2017;12(2):e0171425. doi:10.1371/journal.pone. 0171425

38. Xi G, Keep RF, Hoff JT. Mechanisms of brain injury after intracerebral haemorrhage. Lancet Neurol. 2006;5(1):53-63. doi:10.1016/ S1474-4422(05)70283-0

39. Clement T, Rodriguez-Grande B, Badaut J. Aquaporins in brain edema. J Neurosci Res. 2020;98(1):9-18. doi:10.1002/jnr.24354

40. Manley GT, Fujimura M, Ma T, et al. Aquaporin-4 deletion in mice reduces brain edema after acute water intoxication and ischemic stroke. Nat Med. 2000;6(2):159-163.

41. Saadoun S, Papadopoulos MC. Aquaporin-4 in brain and spinal cord oedema. Neuroscience. 2010;168(4):1036-1046.

42. Walcott BP, Kahle KT, Simard JM. Novel treatment targets for cerebral edema. Neurotherapeutics. 2012;9(1):65-72. doi:10.1007/ s13311-011-0087-4

43. Kim JY, Ko AR, Hyun HW, Kang TC. ETB receptor-mediated MMP-9 activation induces vasogenic edema via ZO-1 protein degradation following status epilepticus. Neuroscience. 2015;304:355-367. doi:10.1016/j.neuroscience.2015.07.065

44. Pan J, Qu M, Li Y, et al. MicroRNA-126-3p/-5p overexpression attenuates blood-brain barrier disruption in a mouse model of middle cerebral artery occlusion. Stroke. 2020;51(2):619-627. doi:10.1161/ STROKEAHA.119.027531
Journal Citation Reports/Science Edition, EMBase, Scopus and the Elsevier Bibliographic databases. The manuscript management system is completely online and includes a very quick and fair peer-review system, which is all easy to use. Visit http://www.dovepress.com/ testimonials.php to read real quotes from published authors. 